\title{
Assessing sleep, travelling habits and jet lag in kite surfers according to competition level
}

\author{
Maria-Raquel G. Silva ${ }^{\mathrm{a}, \mathrm{b}}$, António Pascoal ${ }^{\mathrm{a}}$, Hugo-Henrique Silva ${ }^{\mathrm{c}}$ and Teresa Paiva ${ }^{\mathrm{d}}$ \\ ${ }^{a}$ Faculty of health sciences, University Fernando Pessoa, Oporto, Portugal; bResearch Centre for Anthropology \\ and health, University of coimbra, coimbra, Portugal; 'Portuguese ministry of education, Lisbon, Portugal; \\ ${ }^{\mathrm{d}}$ CENC, Sleep Medicine Center, lisbon, Portugal
}

Corresponding author:

Maria-Raquel G. silva

raquel@ufp.edu.pt

\begin{abstract}
This study evaluated sleep duration, travelling habits and jet lag effects in kite surfers according to their competition level. Ninety- four male kite surfers ( $34.3 \pm 8.8$ years) were evaluated through an online questionnaire in order to collect information on training volume, clinical history, anthropometric profile, sleep habits, fluid and fruit intake and jet lag effects on athletic performance. Mean sleep duration was $07 \mathrm{~h} 19 \mathrm{~min} \pm 01 \mathrm{~h} 12 \mathrm{~min}$ on weekdays with

$82.3 \%$ sleeping less than $8 \mathrm{~h} /$ night. Sleep duration was less on weekdays $(p=0.002)$ and weekends $(p=0.011)$ in kite surfers' squad members (SM) compared to no squad members (NoSM). Greater jet lag symptoms were reported following west-to-east flights. Kite surfers with SMarrived earlier at the competition destination $(p=0.019)$, were more likely to implement strategies to minimize travel effects $(p=0.003)$, but reported more symptoms of jet lag than did NoSM $(p=0.041)$. Travel effects were positively correlated with the distance travelled and negatively correlated with sleep duration on weekdays and water intake during travel to an international kite surfing competition. Jet lag negatively influenced kite surfers'athletic performance with greater symptoms following west-to-east travel in both SM and NoSM.
\end{abstract}

Keywords: sleep, jet lag, circadian rhythm, fluids, travelling athlets

\section{Introduction}

Kitesurfing has been considered a high-risk sport with a growing number of participants worldwide (Bryja 2008). In 2012, the number of kite surfers was estimated at 1.5 million (Nebas \& Heller 2014). Although this adventure and extreme sport is relatively new (Pikora et al. 2012), first reported as being performed in 1996 (Exadaktylos et al. 2005), kitesurfing was voted as a substitute for windsurfing in the Olympic Games held in 2016, in Rio de Janeiro, Brazil (Nebas \& Heller 2014).

This sport combines characteristics of three main water sports: windsurfing, surfing and wakeboarding (Vercruyssen et al. 2009). The apparatus consists of a large controllable kite with a handlebar connected to the kite surfer's harness, and a small board with footpads and straps for riding over the water; athletes are pulled over the water surface, performing jumps and several risky elements in the air even in conditions of light wind (Bourgois et al. 2014; Nebas \& Heller 2014). A kitesurfing competition can be performed in two main categories in accordance with the type of elements involved - namely, crossing (sideways transportation over the surface of the water) and freestyle (jumps and pop tricks) (Bourgois 2014). The few scientific data suggest that crossing is sustained by aerobic metabolism and is of a moderately intense activity $\left(65-70 \% \mathrm{VO}_{2} \max\right.$ ) (Vercruyssen et al. 
2009). Freestyle is sustained by both aerobic and anaerobic metabolism (Clua et al. 2014) and is considered an intense activity (80-90\% $\mathrm{VO}_{2} \max$ (Camps et al. 2011).

To the best of our knowledge, there are no published data concerning sleep or fluid intake in kite surfers. The few scientific data available concern: biomechanical (Bourgois et al. 2014) and physiological aspects (Vercruyssen et al. 2009; Camps et al. 2011; Clua et al. 2014); comfort and safety of the equipment design (lundgren et al. 2012; Nebas \& Heller 2014); and injuries sustained (lundgren et al. 2012; Driessen et al. 2015).

With the increasing popularity of this sport worldwide, kite surfers tend to travel across different time zones in order to compete. For example, the World Kite Tour's calendar for 2016 is planned to take place as follows: France (April), Venezuela (May), Spain (June), Sweden (July), Canary Islands (August), Germany (August/September) and South Africa (December). In fact, while travelling, kite surfers experience a disruption of circadian rhythm, known as jet lag, which can negatively affect their sleep, appetite, mood and cognitive and physical performance (Reilly 2007; Erlacher et al. 2011; Schaal et al. 2011; Halson 2014). Nevertheless, the need for adequate sleep is mandatory. Sleep has been considered the single best recovery strategy for elite athletes because it improves the immune and endocrine systems and so presents a restorative and recuperative effect on athletic recovery. Insufficient sleep may impair these systems with negative consequences for athletic performance (Silva \& Paiva 2015a), especially in injured athletes and during periods of competition, stress or travel (Halson 2008).

It has also been highlighted that appropriate eating habits along with sufficient sleep are important for athletes' health (Silva \& Paiva 2015b), recovery and success (Silva \& Paiva 2015a), especially when travelling (Silva \& Paiva 2015c). Indeed, high-performance athletes face an immune function disturbance with a higher probability of infection; this is enhanced by intense training, deficient nutrition, sleep restriction, travel and changed daily routines (Gleeson \& Williams 2013).

Depending on their level, kite surfers normally travel to different time zones for competition; thus, not only appetite, but also their sleep and athletic performance can be negatively affected by jet lag (Halson 2014; Silva \& Paiva 2015c), even though sleep, eating, drinking and training can be used as external factors to regulate the light-dark cycle and minimize jet lag effects (Halson 2014; Fullagar et al. 2015). In addition, the dry air on board of airconditioned vehicles (car, bus and/or plane) can increase athletes' dehydration; thus, an increase of fluid intake is highly recommended, such as water, juices and soft drinks (Reilly et al. 2007). On the other hand, there is also a circadian variation in gastrointestinal function associated with jet lag syndrome (Reilly et al. 2007; Silva \& Paiva 2015c). Therefore, fruit intake, such as fruit juices, dried fruit and peeled fruit (Reilly et al. 2007), is an important strategy to prevent travellers' gastrointestinal discomfort because of its high levels in fibre and it is an easy way for travelling athletes to consume vitamins, mineral salts and water (Silva \& Paiva 2015b). 
Therefore, this study aimed to evaluate, through an online questionnaire, the effect of competition level upon sleep duration, travel habits and jet lag in adult kite surfers.

\section{Methods}

\subsection{Participants}

A cross-sectional survey was conducted on 94 male kite surfers who volunteered to participate in the study (mean \pm sd: age, $34.3 \pm 8.8$ years; weight, $74.2 \pm 11.8 \mathrm{~kg}$; height, $1.76 \pm 0.08 \mathrm{~m}$ ). They had regularly competed in between two and six national and international events per year for at least the previous two years. Relevant questionnaire items were identified from the scientific literature (Spitzer et al. 1999; Waterhouse et al. 2007) and adjusted to kite surfing practices and language. This questionnaire was available in three languages, namely: English, Spanish and Portuguese, and reviewed by a panel of athletes and experts in nutrition, sport and neuroscience. Kite surfers were recruited through personal contacts by one of the authors, who is a kite surfer; of the 116 athletes who were approached, the response rate of males was $81.0 \%$. Female data are not presented in this study due to the very small size of the sample (the response rate being only $5.2 \%$ ).

To recruit an adequate number of participants, two groups of participants, organized by squad membership, were used. Due to different levels of participation in the sport, each athlete was categorized as a squad member (SM) or not a squad member (NoSM). Forty-four of the participants belonged to an international supported team system that was part of the International Kiteboarding Association, and so were considered as SM. Fifty athletes did not belong to any supportive organization; however, they were dedicated athletes with a long history of involvement in kite surfing, and so they were considered as NoSM. The kite surfers were from North America, South America, Europe and Africa. Athletes with SM prac- tised freestyle (70.5\%) and crossing (29.5\%). In the NoSM group, $72 \%$ practiced freestyle and $28 \%$ crossing.

The volunteers were asked to complete an online questionnaire which asked about their typical behaviour regarding the longest journey they had taken in the preceding 12 months in order to compete. Information was obtained regarding: anthropometric profile, training volume, clinical history, sleep habits, fluid and fruit intake, distance travelled for competition, effects of travelling upon general well-being, effects on athletic performance of any jet lag and strategies to minimize the effect of jet lag on athletic performance.

The study design was approved by the Ethics Committee of the University Fernando Pessoa (Oporto, Portugal) and informed consent was obtained from all participants.

\subsection{Training and competition data}

Training data included running, muscle-building exercise and kitesurfing sessions. Several parameters were obtained: the number of training sessions per week and the number of hours of training sessions per day (from which the number of hours training per week was calculated). Comparisons are presented between those who was/ was not a SM. 


\subsection{Anthropometric and clinical data}

Weight and height were self-reported. Body mass index (BMI) was calculated as weight/ squared height $\left(\mathrm{kg} / \mathrm{m}^{2}\right)$. Anthropometric standards from Frisancho (2008) were used for weight, height and BMI. Data relating to any kind of disease, or medication, vitamin or mineral supplements being taken or to any other type of supplement were collected.

\subsection{Sleep}

Mean bedtimes and wake times during the week and at the weekend were obtained, considering the preceding 12 months. Sleep variability was measured by the difference in sleep duration between weekends and weekdays. Poor sleep duration was defined as a mean total sleep duration of less than 08 h 30 min per day (Fullagar et al. 2015; Silva \& Paiva 2015a).

\subsection{Statistical analysis}

The characteristics of the participants are described as proportions for categorical variables and as mean and standard deviation for continuous variables (age, training volume and sleep duration). To test for differences in sports characteristics, food and sleep habits of athletes who had/did not have SM, $t$-tests were applied. Chi-squared test was performed for comparisons of frequencies between groups. Since there was no control group, the results were compared with reference data and with results from other published studies. Spearman correlation coefficients were used to determine associations between categorical and continuous variables. Bivariate (Pearson) correlations were run on continuous measures of demographics, anthropometry, training, sleep, travelling and fluid and fruit intake. linear regression analysis was used to evaluate predictors of travelling effects prior to competition. Standardized predicted values and residuals were computed iteratively and by adding variables considered significant by correlation analysis using the forward stepwise multiple regression method. The significance level was $5 \%(p<0.05)$. Data were analysed using IBM SPSS statistical software version 21.0 for Windows (New york, USA).

\section{Results}

Participants practiced kitesurfing for a mean of $4.0 \pm 5.1 \mathrm{~h} /$ week and did $4.5 \pm 6.3 \mathrm{~h}$ /week of running or muscle-building exercise, the total training volume being $9.8 \pm 9.2 \mathrm{~h} /$ week. Training volume as well as physical training was significantly higher per week in SM than in $\operatorname{NoSM}(p<0.05$, Table 1$)$.

Regarding diseases and medication, 5\% of the SM reported suffering from diabetes type I or asthma and were taking the appropriate medication (anti-inflammatory non-steroids); $12 \%$ of the NoSM suffered from asthma or hypertension and were taking suitable medication as well as anti-depressives, anti-inflammatory non-steroids and dietary supplements. No sleep medication was reported by the participants. Surprisingly, 77.3\% NoSM were taking nutritional supplements (multivitamins, calcium, iron, magnesium and proteins) and only $22.7 \%$ SM were taking multivitamins and proteins. 
Table 1. age, training volume, anthropometric profile and self-reported sleep duration of kite surfers $(n=94)$, according to squad membership (sm, squad members; and Nosm,no squad members).

\begin{tabular}{lccc}
\hline & SM $(n=44)$ & NoSM $(n=50)$ & $P^{*}$ \\
& Mean \pm sd (min.-max.) & Mean \pm sd (min.-max.) & \\
\hline age (years) & $33.3 \pm 8.8(18-56)$ & $35.1 \pm 8.8(21-57)$ & 0.659 \\
Weight (kg) & $74.4 \pm 10.8(52-98)$ & $74.1 \pm 12.7(46-95)$ & 0.255 \\
height (m) & $1.77 \pm 0.7(1.62-1.95)$ & $1.74 \pm 0.8(1.52-1.95)$ & 0.960 \\
Bmi (kg/m²) & $23.7 \pm 2.6(18.4-32.0)$ & $24.2 \pm 2.8(18.1-30.4)$ & 0.564 \\
Kitesurfing training (times/week) & $2.3 \pm 1.6(3.0-7.0)$ & $1.5 \pm 1.2(2.0-6.0)$ & $0.024^{*}$ \\
Kitesurfing training (h/day) & $2.0 \pm 1.5(3.0-5.0)$ & $1.5 \pm 1.3(2.0-4.0)$ & 0.902 \\
Kitesurfing training (h/week) & $5.6 \pm 6.3(8.0-25.0)$ & $2.5 \pm 3.0(3.0-10.0)$ & $<0.0005^{* *}$ \\
Physical training (times/week) & $2.6 \pm 2.3(3.0-7.0)$ & $2.3 \pm 1.8(1.0-6.0)$ & 0.093 \\
Physical training (h/day) & $1.3 \pm 1.4(3.0-7.0)$ & $1.0 \pm 0.9(1.0-3.0)$ & $0.018^{*}$ \\
Physical training (h/week) & $5.2 \pm 8.1(3.0-18.0)$ & $3.3 \pm 3.9(3.0-10.0)$ & $0.040^{*}$ \\
total training (h/week) & $12.7 \pm 10.9(3.0-29.0)$ & $5.8 \pm 5.3(3.0-14.0)$ & $0.008^{* *}$ \\
Bedtime, weekdays (clock time, h:min) & $00: 54 \pm 1: 10(23: 30-02: 00)$ & $01: 18 \pm 1: 35(23: 30-03: 00)$ & 0.200 \\
Bed time, weekend days (clock time, h:min) & $02: 26 \pm 0: 58(23: 30-03: 00)$ & $02: 51 \pm 1: 04(23: 30-05: 00)$ & 0.629 \\
Waking time, weekdays (clock time, h:min) & $06: 16 \pm 0: 26(05: 00-09: 00)$ & $07: 52 \pm 0: 14(07: 00-10: 00)$ & $0.038^{*}$ \\
Wake time, weekend days (clock time, h:min) & $07: 59 \pm 0: 45(07: 30-10: 00)$ & $08: 41 \pm 0: 55(08: 00-11: 00)$ & $0.030^{*}$ \\
sleep time, weekdays (h:min) & $6: 28 \pm 1: 05(5: 43-7: 30)$ & $8: 30 \pm 1: 24(7: 00-9: 30)$ & $0.002^{* *}$ \\
sleep time, weekend days (h:min) & $7: 42 \pm 1: 08(7: 00-9: 30)$ & $8: 52 \pm 1: 21(8: 00-11: 00)$ & $0.011^{*}$ \\
\hline
\end{tabular}

Notes: Bmi: body mass index. Physical training includes running and muscle-building exercises.

${ }^{\#} \mathrm{sm}$ vs. Nosm by independent samples $t$-tests.

${ }^{*} p<0.05 ; * *^{*}<0.01$.

Kite surfers'weight, height and BMI groups were below normal for their age (25th to 50th percentiles) in both groups (SM and NoSM), with exception for height in SM, which was normal to slightly above normal for age (50th to 75 th percentiles) (Table 1).

The weekly durations of kite surfing training $(p<0.01)$, physical training $(p<0.05)$ and, therefore, total training duration $(p<0.01)$ were greater in kite surfers' SMcompared to NoSM (Table 1).

Mean sleep duration of all participants was 07 h $19 \pm 01$ h 12 on weekdays with $82.3 \%$ of kite surfers sleeping less than $8 \mathrm{~h}$ per night. On weekends, only $38.2 \%$ of kite surfers slept less than $8 \mathrm{~h}$ per night, which was probably due to later wake times at the weekend. Selfreported sleep duration was less on both weekdays $(p=0.002)$ and weekends $(p=0.011)$ in SM compared to NoSM. This may be due to earlier wake times in SM $(p=0.030$, Table 1$)$.

The mean travel distance for competition was $14,489 \pm 3629 \mathrm{~km}$ in SM and $2264 \pm 781 \mathrm{~km}$ in NoSM.

Athletes'SM arrived earlier at the competition's destination than did athletes $\operatorname{NoSM}(p$ $=0.019$, Table 2). Travelling effects depended upon $\operatorname{SM}(p=0.023)$, and were mainly sleep disruption, fatigue, appetite loss and headaches (Table 2). As expected, greater jet lag symptoms were reported following west-to-east travel in both SM and NoSM; jet lag negatively influenced kite surfers' athletic performance $(p=0.041$, Table 2$)$ by causing fatigue, daytime sleepiness, reductions in concentration, resistance and reaction time. Also, there was dehydration in two NoSM kite surfers and lethargy in one of this group.

While $66 \%$ of kite surfers drank fluid (not counting water) during travel, $51 \%$ reported consuming less than 0.5-1 water, and only $25.5 \%$ ate fruit (Table 3). Fluid and fruit intake was greater in SM (95.5 and 45.5\%, respectively) than in NoSM (48.0 and 8.0\%, respectively) ( $p$ $<0.05$, Table 3). Surprisingly, $13.6 \%$ of SM and $58.0 \%$ of NoSM did not drink water or any other fluid, respectively. Coffee was the second most consumed drink (51.6\%) and alcohol was the 
Table 2. Jet lag effects on the athletic performance of kite surfers $(n=94)$, according to squad membership (sm, squad members; and Nosm, no squad members).

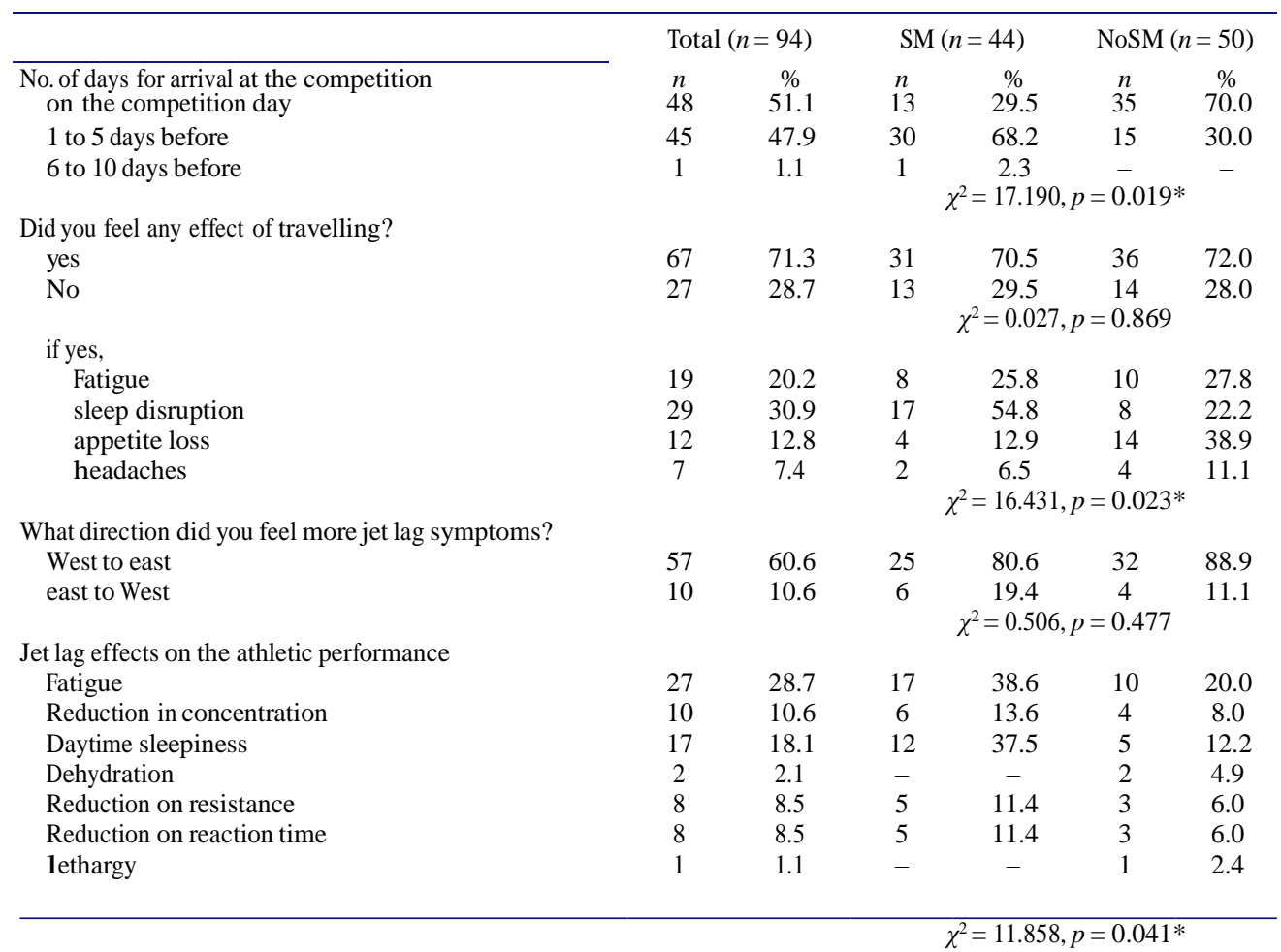

Notes: squad membership differences determined by chi-squared tests. ${ }^{*} p<0.05$.

one most avoided (56.4\%, Table 3). Energy drinks were not consumed by most of the athletes (77.3\% in SM and $94.0 \%$ in NoSM), but were consumed mainly after training or competition.

Kite surfers'SM were more likely to implement strategies to minimize travel effects than $\operatorname{NoSM}(p=0.003$, Table 3 ); only eating and drinking were mentioned by the latter group as strategies implemented to regulate their circadian rhythm, but $38.6 \%$ of the SM group considered sleeping and training, in addition to eating and drinking, as the most effective strategies to rapidly minimize jet lag effects on their performance. In fact, sleeping was the strategy most used (58.8\% of participants, Table 3). No pharmacological interventions, including melatonin, were mentioned by kite surfers.

Pearson's correlation coefficients $(r)$ indicate that travel effects were positively correlated with weight $(r=0.205, p=0.47)$, BMI $(r=0.203, p=0.04)$ and distance travelled for competition $(r=0.447, p<0.0005)$. On the other hand, travel effects were negatively correlated with the daily volume of running or muscle-building exercises $(r=-0.257, p=0.012)$, the number of weekly hours of running or muscle-building exercises $(r=-0.337, p=0.001)$, the number of times per week an individual went kitesurfing $(r=-0.258, p=0.012)$, the weekly volume of kitesurfing $(r=-0.230, p=0.026)$, the total volume of training per week $(r=-0.336$, $p=0.001)$, sleep on weekdays $(r=-0.384, p<0.0005)$ and water intake $(r=-0.389$, $p<0.0005)$. 
Table 3. Fluid and fruit intake during travel and strategies to minimize jet lag effects on the athletic performance of kite surfers $(n=94)$, according to squad membership (sm, squad members; and Nosm,no squad members).

\begin{tabular}{|c|c|c|c|c|c|c|}
\hline \multirow[b]{2}{*}{ Water consumption } & \multicolumn{2}{|c|}{ Total $(n=94)$} & \multicolumn{2}{|c|}{$\mathrm{SM}(n=44)$} & \multicolumn{2}{|c|}{$\operatorname{NoSM}(n=50)$} \\
\hline & $n$ & $\%$ & $\bar{n}$ & $\%$ & $n$ & $\%$ \\
\hline yes & 49 & 52.1 & 42 & 95.5 & 24 & 48.0 \\
\hline \multirow[t]{2}{*}{ No } & 45 & 47.9 & 2 & 4.5 & 26 & 52.0 \\
\hline & & & \multicolumn{4}{|c|}{$\chi^{2}=24.160, p=0.012 *$} \\
\hline \multicolumn{7}{|l|}{ if yes, } \\
\hline$<0.51$ & 25 & 51.0 & 20 & 47.6 & 17 & 70.8 \\
\hline $0.5-1.01$ & 14 & 28.6 & 12 & 28.6 & 7 & 29.2 \\
\hline $1.0-2.01$ & 8 & 16.3 & 8 & 19.0 & - & - \\
\hline$>2.01$ & 2 & 4.1 & 2 & 4.8 & - & - \\
\hline \multicolumn{7}{|c|}{$\begin{array}{l}\text { other fluid (coffee, tea and/or } \\
\text { soda) }\end{array}$} \\
\hline yes & 62 & 66.0 & 30 & 68.2 & 47 & 94.0 \\
\hline \multirow[t]{2}{*}{ No } & 32 & 34.0 & 4 & 9.1 & 3 & 6.0 \\
\hline & & & \multicolumn{4}{|c|}{$\chi^{2}=0.182, p=0.669$} \\
\hline \multicolumn{6}{|l|}{ if yes, } & 44.6 \\
\hline tea & 9 & 14.5 & 8 & 26.7 & 1 & 2.1 \\
\hline soda & 9 & 14.5 & 4 & 13.3 & 15 & 31.9 \\
\hline alcohol & 12 & 19.4 & 7 & 23.3 & 10 & 21.3 \\
\hline \multicolumn{7}{|l|}{ Fruit consumption } \\
\hline yes & 24 & 25.5 & 20 & 45.5 & 4 & 8.0 \\
\hline \multirow[t]{2}{*}{ No } & 70 & 74.5 & 24 & 54.5 & 46 & 92.0 \\
\hline & & & \multicolumn{4}{|c|}{$\chi^{2}=17.953, p=0.002^{* *}$} \\
\hline \multicolumn{7}{|l|}{ if yes, } \\
\hline $1-2$ pieces & 21 & 87.5 & 17 & 85.0 & 4 & 100 \\
\hline 3-4 pieces & 2 & 8.3 & 2 & 10.0 & - & - \\
\hline$>4$ pieces & 1 & 4.2 & 1 & 5.0 & - & - \\
\hline \multicolumn{7}{|c|}{ avoidance of any food or drink } \\
\hline yes & 39 & 41.5 & 17 & 38.6 & 22 & 44.0 \\
\hline \multirow[t]{2}{*}{ No } & 55 & 58.5 & 27 & 61.4 & 28 & 56.0 \\
\hline & & & \multicolumn{4}{|c|}{$\chi^{2}=0.506, p=0.477$} \\
\hline \multicolumn{7}{|l|}{ if yes, } \\
\hline Water & 9 & 23.1 & 6 & 35.3 & 3 & 13.6 \\
\hline coffee & - & - & - & - & - & - \\
\hline tea & 8 & 20.5 & 2 & 11.8 & 6 & 27.3 \\
\hline alcohol & 22 & 56.4 & 9 & 52.9 & 13 & 59.1 \\
\hline \multicolumn{7}{|c|}{$\begin{array}{l}\text { Did you use any special strategy } \\
\text { to minimize the jet lag effects } \\
\text { on athletic performance? }\end{array}$} \\
\hline yes & 19 & 20.2 & 17 & 38.6 & 2 & 4.0 \\
\hline \multirow[t]{2}{*}{ No } & 75 & 79.8 & 27 & 61.4 & 48 & 96.0 \\
\hline & & & \multicolumn{4}{|c|}{$\chi^{2}=15.061, p=0.003^{* *}$} \\
\hline \multicolumn{7}{|l|}{ if yes, } \\
\hline sleeping & 10 & 52.6 & 10 & 58.8 & - & - \\
\hline eating and drinking & 7 & 36.8 & 5 & 29.4 & 2 & 100.0 \\
\hline training & 2 & 10.5 & 2 & 11.8 & - & - \\
\hline
\end{tabular}

Note: squad membership differences determined by chi-squared tests. ${ }^{*} p<0.05 ; * * p<0.01$.

In order to evaluate possible predictors of "travel effect" prior to competition, a regression analysis was performed. Travel effect was defined as the amount of reported symptoms during travelling for competition. Weight, BMI and training habits were excluded since they were not significant predictors. Three models were found and the last (Model 3) was the best, explaining $66.3 \%$ of the variance in kite surfers' travel effects $(F=8.290, p<0.001$ - Table 4$)$. This model found that kite surfers' travel effects were dependent on the distance travelled 
Table 4. linear regression analysis for the prediction of travel effects in kite surfers.

\begin{tabular}{|c|c|c|c|c|c|}
\hline & $R^{2}$ adjusted & $F$ & $B$ & $\mathrm{SE}$ of $B$ & $\beta$ \\
\hline model 1 & 0.191 & $23.005 * *$ & $0.027^{\mathrm{a}}$ & $0.671^{\mathrm{b}}$ & \\
\hline Distance for competition & & & 1.277 & 0.266 & $0.447 * *$ \\
\hline model 2 & 0.316 & $17.716^{* *}$ & $-1.450^{\mathrm{a}}$ & $0.710^{\mathrm{b}}$ & \\
\hline Distance for competition & & & 1.222 & 0.245 & $0.428 * *$ \\
\hline sleep on weekdays & & & -0.655 & 0.156 & $-0.362 * *$ \\
\hline model 3 & 0.663 & $8.290 * *$ & $-3.244^{\mathrm{a}}$ & $0.925^{\mathrm{b}}$ & \\
\hline Distance for competition & & & 1.098 & 0.240 & $0.385 * *$ \\
\hline sleep on weekdays & & & -0.558 & 0.154 & $0.308 * *$ \\
\hline Water intake & & & -2.120 & 0.736 & $0.248^{*}$ \\
\hline
\end{tabular}

${ }^{\mathrm{a}}$ and ${ }^{\mathrm{b}}$ are the mean and the se, respectively, of the constant term.

$*_{p}<0.05 ; * *<0.001$.

for competition, D, sleep duration on weekdays, SDWeek, and water intake during travel, WI (see model 3, Table 4). The result was:

Kite surfers' travel effects $=-3.244+(1.098 \times \mathrm{D})-(0.558 \times$ SDWeek $)-(2.120 \times \mathrm{WI})$.

\section{Discussion}

This study provides the first data on sleep duration, travelling habits and jet lag effects in kite surfers. The kite surfers' response rate, in view of the demands of the competitions and travel environment, is adequate, and the number of kite surfers studied is higher than in most published data. Our study involved evaluation of athletes while travelling, and so this prevented the use of a control population.

Our findings emphasize a greater weekly training duration (and potentially load) in SM, but reduced self-reported sleep duration, compared to NoSM. Though not measured, it could have an impact on athletes' training quality, recovery, injury and illness (Halson 2014; Silva \& Paiva 2015a). This may also be due to training times since early morning training and evening training may disrupt sleep (Czeisler 2015; Fullagar et al. 2015). Self-reported sleep duration in SM $(06: 28 \pm 01: 05 \mathrm{~h})$ was similar to that observed in 70 elite athletes from seven different sports screened by actigraphy (06:30 \pm 01:24 h, Sargent et al. 2014). However, sleep duration reported in $\operatorname{NoSM}(08: 30 \pm 01: 24 \mathrm{~h})$ was similar with that observed in 26 elite athletes from Olympic sports also monitored by actigraphy $(08: 36 \pm 00: 53 \mathrm{~h}$, leeder et al. 2012).

In spite of considering sleep as an important resource for the athlete's success and recovery (Halson 2008; Sargent et al. 2014; Silva \& Paiva 2015a, 2015c), few studies have explored sleep in athletes, distinguishing between sleep during pre-competition practice and the competition itself. To the best of our knowledge, no such studies exist in kite surfers. Other authors evaluated sleep habits of German athletes before an important competition (Erlacher et al. 2011); sleep habits of Brazilian Paralympic athletes before the 2008 Olympic Games (Silva et al. 2012); the pre-competitive sleep behaviour of marathon runners (1astella et al. 2014a); sleep habits of male endurance cyclists during training phase, before competition and during competition (1astella et al. 2014b); sleep complaints of elite Australian athletes (including three gymnasts, whose gender or discipline of gymnastics is not mentioned) 1 month prior to and 7 months following the 2012 Olympic Games (Juliff et al. 2015); and poor pre-competitive sleep habits of high-performance gymnasts (Silva \& Paiva 2015a). A case study with one sailor (who had more than 10 years sailing experience in severe 
conditions, and whose goal was to be the first person to cross the Pacific Ocean on a catamaran of less than $6 \mathrm{~m}$ ) concluded that the sailor's deliberate strategy of sleeping $5.4 \mathrm{~h}$ per day was sufficient to achieve his goal (Hagin et al. 2012). On the other hand, Galvani et al. (2015) evaluated eight male sailors $(46.3 \pm 3.4$ years; $85.4 \pm 12.5 \mathrm{~kg} ; 180 \pm 13 \mathrm{~cm})$ during a double-handed offshore competition of 500 nautical miles and observed that they slept $5 \pm 1.4$ times per day for $36 \pm 9$ min each sleeping period, which indicates that there would have been a build-up of a considerable sleep debt, presumably with negative consequences for performance. Hurdiel et al. (2014) also concluded that 12 professional male sailors demonstrated poor sleep during one of the three single-handed races of 150,300 and 350 nautical miles (nominally $24-50 \mathrm{~h}$ in duration), with negative consequences upon athletic performance. Despite differences in the mentioned studies - namely, sport modality, athletes' category and nationality, and type and duration of the investigation - the similarity of results with regard to the inadequacy of sleep duration in athletes is impressive.

Considering that the circadian rhythm system, physiologically influenced by the suprachiasmatic nucleus located in the hypothalamus (which in turn, is sensitive to light cues, social schedules, including different time-zones), plays a modulatory role in the timing of melatonin release (Dijk et al. 1999; Dahl \& lewin 2002; Reilly 2007; Williams 2011), our results confirm the influence of the jet lag on athletic performance. In fact, fatigue and sleep disruption were the most commonly reported jet lag symptoms and greater disturbances on their circadian rhythm were reported when travelling eastwards since a phase advance is required, while a phase delay is required following a flight westwards (Reilly et al. 2007; Silva $\&$ Paiva 2015c).

The general finding from sleep medicine, that athletes who compete at an international level can suffer more from sleep disruptions (Reilly \& Waterhouse 2007; Williams 2011; Silva \& Paiva 2015a, 2015c), seems to be reflected in our results.

As kite surfers'SM travelled a greater distance, they might have travelled across different time zones to compete in an environment that may be geographically distant and different from the home base (Silva \& Paiva 2015a, 2015b); thus, they generally reported more symptoms of jet lag compared to NoSM. This factor may contribute to more extensive strategies used by SM to regulate their circadian rhythms. Kite surfers' behaviours at the new destination, such as sleeping (Halson 2008, 2014; lau et al. 2010; Fullagar et al. 2015), eating and drinking (Reilly \& Waterhouse 2007; Halson 2008, 2014; Fullagar et al. 2015), and training (Fullagar et al. 2015; Uchida et al. 2012; Silva \& Paiva 2015c), could be used as important "zeitgebers" (time-givers for body clock's readjustments by rhythmic cues in the environment) at the new time zone (Waterhouse et al. 2007; Silva \& Paiva 2015a).

Despite the observation that SM were more likely to implement strategies to minimize travel effects than NoSM, including arriving earlier at the destination and greater fluid intake during travel, travel effects were dependent on the distance travelled for competition, sleep duration on weekdays and water intake during travel. Water intake was insufficient, with a negative correlation on kite surfers' well-being, as shown by our results. Thirst is a poor indicator of fluid needs (Jeukendrup \& Cronin 2011; Silva \& Paiva 2015b), especially when travelling by air. The dry air of the aircraft leads to an increased loss of moisture from respiration, causing a gradual and unperceived dehydration; thus, it is estimated that athletes should drink an extra of 15-20 ml for each hour of flight (Reilly et al. 2007). This hydration should not be too late in the evening in order to avoid waking from sleep to micturate (Silva $\&$ Paiva 2015c). Typical drinks should be water and palatable drinks such as fruit juices and 
lemonades, rather than cola drinks, tea or coffee, because of the diuretic and stimulant effects of the caffeine presented in this last group (Reilly et al. 2007). The stimulant effect of caffeine can modify the endogenous secretion of melatonin by inhibiting $\alpha 2 \mathrm{G}$ adenosine receptors in the pineal gland; thus, its consumption in the evening may interfere with sleep, while in the morning, it can help the body clock to readjust (Beaumont et al. 2004). In long-haul flights, particularly during eastwards flights, meals become less palatable; this might be a result of dehydration, modifications to taste mechanisms, jet lag or tiredness (Reilly et al.

2007; Waterhouse et al. 2007). In addition, an athlete's energy and nutritional needs may not be met by food offered by airlines; therefore, athletes need to plan their meals and hydration in advance, especially if travelling by air.

Besides optimal hydration, fruit intake is essential to minimize gastrointestinal distress and regulate appetite (Reilly \& Waterhouse 2007; Silva \& Paiva 2015b). With only $25.5 \%$ of the traveller kite surfers eating fruit and having insufficient fluid intake, we must assume that nutritional education of this group is needed.

To overcome jet lag effects on athletic performance, some strategies should be implemented as follows: flying to the new country in plenty of time to adapt to the new local time (travelling to West will result in premature waking and travelling to East will result in initial difficulties in sleeping but less likelihood of premature waking); reducing the training volume in the days immediately after the flight; and monitoring sleep and fatigue and adjusting training accordingly. Pharmacological intervention related to the use of chronobiotics and soporifics (melatonin and benzodiazepines) is not recommended for healthy young athletes (Williams 2011; Silva \& Paiva 2015c; Silva \& Paiva 2015a) due to difficulties in estimating the optimal time of ingestion (Reilly \& Waterhouse 2007).

Since reduced sleep duration was also reported by our travelling kite surfers, sleep hygiene recommendations should also be followed. These include: limitation of activities that arouse adolescents at bed time (watching TV, using the computer, Internet or phone); setting and adhering to a regular sleep time; avoid practicing intense physical exercise after 8:00 pm; and evaluation of sleep patterns in order to improve individual performance (Williams 2011; Silva \& Paiva 2015c). Athletes should also avoid alcohol intake near bedtime and limit caffeine intake after 6:00 pm - caffeine is an ergogenic aid that stimulates the nervous system and it is found in coffee, tea and energy drinks (le Meur et al. 2013; Silva \& Paiva 2015c).

The limitations of this study should be taken into account when interpreting these results. First, the reliance of self-report weight and height may be compromised due to both its subjective character as well as the participants'body perception associated with sport demands; this may have introduced bias into the study. Second, these results may reflect the use of a self-report method of data collection, where participants may under-report negative behaviours, including daytime sleepiness, fatigue, pain, reduction of athletic performance, hunger, gastrointestinal discomfort, nauseas and vomiting. Third, sleep characteristics, such as quality and daytime sleepiness, and dietary intake related to jet lag and athletic performance were not explored. Fourth, although relevant questionnaire items were identified from the scientific literature (Spitzer et al. 1999; Waterhouse et al. 2007) and adjusted to kitesurfing practice and language, these might limit the questionnaire's accuracy in assessing behaviour in the preceding 12 months.

However, the online survey was effective as a method for collecting data and should be utilized in larger studies (Pikora et al. 2011). Fifth, the lack of scientific literature studying sleep and food habits among these athletes makes it difficult to compare and generalize 
the results to the wider population. Therefore, it remains essential to identify athletes at risk of sleep disruption and inadequate food and fluid intake during travel; thus, educational programmes and preventive strategies should be implemented.

\section{Conclusions}

The unwanted effects of travel in kite surfers were positively correlated with the distance travelled and negatively correlated with sleep duration on weekdays and water intake during travel to international kitesurfing competitions. Jet lag negatively influenced kite surfers' athletic performance with greater symptoms following eastwards travel in both SM and NoSM.

Kitesurfing is growing in popularity around the world, evolving and pushing the boundaries of the sport; therefore, specialized studies are needed to monitor kite surfers'sleep and interventions are required to promote a healthy diet and an optimal body composition in them.

\section{Acknowledgements}

All authors were responsible for the conception, design, data analysis and data interpretation of the study and writing the manuscript; M. R. G. Silva and A. Pascoal were also responsible for data collection. Authors thank the kite surfers for their cooperation in this study. The authors are also grateful to the editor and the reviewer for their valuable comments.

\section{Disclosure statement}

No potential conflict of interest was reported by the authors.

\section{Funding}

This work was supported by the National Founds from FCT - Foundation for Science and Technology [project number PEst-OE/SADG/UI0283/2015].

\section{References}

Beaumont M, Batejat D, Pierard C, Van Beers P, Denis JB, Coste O, 1agarde D. 2004. Caffeine or melatonin effects on sleep and sleepiness after rapid eastward transmeridian travel. J Appl Physiol. 96:50-58. doi:http://dx.doi.org/10.1152/japplphysiol.00940.2002.

Bourgois JG, Boone J, Callewaert M, Tipton MJ, Tallir IB. 2014. Biomechanical and physiological demands of Kitesurfing and epidemiology of injury among Kitesurfers. Sports Med. 44:55-66. doi:http://dx.doi. org/10.1007/s40279-013-0103-4.

Bryja J. 2008. Kiteboarding statistics: worldwide participation and sales statistics. SBC Kiteboard online: SBC Kiteboard Magazine.

Camps A, Vercruyssen F, Brisswalter J. 2011. Variation in heart rate and blood lactate concentration in freestyle kytesurfing. J Sports Med Phys Fit. 51:313-321.

Clua E, Bescond PM, Reid D. 2014. Fatal attack by a juvenile tiger shark, Galeocerdo cuvier, on a kitesurfer in New Caledonia (South Pacific). J Foren legal Med. 25:67-70. doi:http://dx.doi.org/10.1016/j. jflm.2014.04.005.

Czeisler CA. 2015. Duration, timing and quality of sleep are each vital for health, performance and safety. Sleep Health. 1:5-8. doi:http://dx.doi.org/10.1016/j.sleh.2014.12.008. 
Dahl RE, 1ewin DS. 2002. Pathways to adolescent health sleep regulation and behavior. J Adoles Health. 31:175-184.

Dijk D-J, Duffy JF, Riel E, Shanahan T1, Czeisler CA. 1999. Ageing and the circadian and homeostatic regulation of human sleep during forced desynchrony of rest, melatonin and temperature rhythms. J Physiol. 516:611-627.

Driessen A, Probst C, Sakka SG, Eikermann C, Mutschler M. 2015. Bilateral carotid artery dissection in a kite surfer by strangulation with the kite lines. Der Unfallchirurg. 118(6):567-570 [in German]. doi:http://dx.doi.org/10.1007/s00113-014-2641-0.

Erlacher D, Ehrlenspiel F, Adegbesan OA, El-Din HG. 2011. Sleep habits in German athletes before important competitions or games. J Sports Sci. 29:859-866. doi:http://dx.doi.org/10.1080/02640 414.2011.565782.

Exadaktylos AK, Sclabas GM, Blake I, Swemmer K, McCormick G, Erasmus P. 2005. The kick with the kite: an analysis of kite surfing related offshore rescue missions in Cape Town, South Africa. British J Sports Med. 39:e26.

Frisancho AR. 2008. Anthropometric standards: an interactive nutritional reference of body size and body composition for children and adults. Ann Arbor: The University of Michigan Press; 2008. Available from: http://babel.hathitrust.org/cgi/pt?id=mdp.39015082696876;view=1 up;seq=3

Fullagar HH, Skorski S, Duffield R, Hammes D, Coutts AJ, Meyer T. 2015. Sleep and athletic performance: the effects of sleep loss on exercise performance, and physiological and cognitive responses to exercise. Sports Med. 45:161-186. doi:http://dx.doi.org/10.1007/s40279-014-0260-0.

Galvani C, Ardigò 1P, Alberti M, Daniele F, Capelli C. 2015. Physical activity, sleep pattern and energy expenditure in double-handed offshore sailing. J Sports Med Phys Fit. 55:1480-1488.

Gleeson M, Williams C. 2013. Intense exercise training and immune function. Nestle Nutr Inst Workshop Ser. 76: 39-50. doi: http://dx.doi.org/10.1159/000350254.

Hagin V, Gonzales BR, Candau RB, Groslambert A. 2012. Influence of a conservative sleep management strategy during a solo Pacific Ocean crossing on anxiety and perceived fatigue: a case study. J Sports Sci. 30:395-402.

Halson S1. 2008. Nutrition, sleep and recovery. Eur J Sport Sci. 8:119-126.

Halson S1. 2014. Sleep in elite athletes and nutritional interventions to enhance sleep. Sports Med. 44:13-23. doi:http://dx.doi.org/10.1007/s40279-014-0147-0.

Hurdiel R, Van Dongen HP, Aron C, McCauley P, Jacolot 1, Theunynck D. 2014. Sleep restriction and degraded reaction-time performance in Figaro solo sailing races. J Sports Sci. 32:172-174.

Jeukendrup A, Cronin 1. 2011. Environmental factors affecting elite young athletes. Med Sport Sci. 56:47-58. doi:http://dx.doi.org/10.1159/000320646.

Juliff IE, Halson S1, Peiffer JJ. 2015. Understanding sleep disturbance in athletes prior to important competitions. J Sci Med Sport. 18:13-18. doi:http://dx.doi.org/10.1016/j.jsams.2014.02.007.

1astella M, lovell GP, Sargent C. 2014a. Athletes' precompetitive sleep behaviour and its relationship with subsequent precompetitive mood and performance. Eur J Sport Sci. 14:S123-S130. doi:http:// dx.doi.org/10.1080/17461391.2012.660505.

lastella M, Roach GD, Halson S1, Martin DT, West NP, Sargent C. 2014. Sleep/wake behaviour of endurance cyclists before and during competition. J Sports Sci. 33:293-299. doi:http://dx.doi.org/ 10.1080/02640414.2014.942690.

1au BC, Collins BSMW, lovell MR. 2010. Sensitivity and specificity of subacute computerized neurocognitive testing and symptom evaluation in predicting outcomes after sports-related concussion. Amer J Sports Med. 39:1209-1216.

1e Meur y, Duffield R, Skein M. 2013. Sleep. In: Hausswirth C, Mujika I, The National Institute of Sport for Expertise and Performance (INSEP), editors. Recovery for performance in sport. Champaing, II: Human Kinetics; p. 99-110.

leeder J, Glaister M, Pizzoferro K, Dawson J, Pedlar C. 2012. Sleep duration and quality in elite athletes measured using wristwatch actigraphy. J Sports Sci. 30:541-545. doi:http://dx.doi.org/10.1080/02 640414.2012.660188.

lundgren 1, Brorsson S, Osvalder A1. 2012. Comfort aspects important for the performance and safety of kitesurfing. Work. 41:1221-1225. 
Nebas T, Heller B. 2014. A smartphone based system for kite and board measurements in Kitesurfing. Proc Eng. 72:477-482.

Pikora TJ, Braham R, Hill C, Mills C. 2011. Wet and wild: results from a pilot study assessing injuries among recreational water users in Western Australia. Int J Inj Contr Saf Promot. 18:119-126.

Pikora TJ, Braham R, Mills C. 2012. The epidemiology of injury among surfers, kite surfers and personal watercraft riders: wind and waves. Med Sport Sci. 58:80-97.

Reilly T. 2007. Circadian rhythms. In: Winter EM, Jones AM, Davison RCR, Bromley PD, Mercer TM, editors. Sport and exercise physiology testing guidelines. Iondon: Routledge; p. 54-60.

Reilly T, Waterhouse J. 2007. Altered sleep-wake cycles and food intake: the Ramadan model. Physiol Behav, 28, 219-228.

Reilly T, Waterhouse J, Burke 1M, Alonso JM, International Association of Athletics Federations. 2007. Nutrition for travel. J Sports Sci. 25:S125-S134.

Sargent C, Halson S1, Roach GD. 2014. Sleep or swim? Early morning training severely restricts the amount of sleep obtained by elite swimmers. Eur J Sport Sci. 14:S310-S315. doi:http://dx.doi.org/ 10.1080/17461391.2012.696711.

Schaal K, Tafflet M, Nassif H, Thibault V, Pichard C, Alcotte M, Toussaint JF. 2011. Psychological balance in high level athletes: gender-based differences and sport-specific patterns. PloS One. 4:1-9. doi:http:// dx.doi.org/10.1371/journal.pone.0019007.

Silva M-RG, Paiva T. 2015a. Poor precompetitive sleep habits, nutrients' deficiencies, inappropriate body composition and athletic performance in elite gymnasts. Eur J Sport Sci. 27:1-10. doi:http://dx.doi. org/10.1080/17461391.2015.1103316.

Silva M-RG, Paiva T. 2015b. Poor precompetitive sleep habits, nutrients' deficiencies, inappropriate body composition and athletic performance in elite gymnasts. Eur J Sport Sci. 16:1-10. doi:http:// dx.doi.org/10.1080/17461391.2014.969323.

Silva M-RG, Paiva T 2015c. Sleep and circadian rhythm in athletes. In: Gymnastics Federation of Portugal, Portuguese Institute of Sport and youth I.P, editors. Sleep, nutrition, circadian rhythm, jet lag and athletic performance [in Portuguese]. lisbon: Gymnastics Federation of Portugal; p. 50-69.

Silva A, Queiroz SS, Winckler C, Vital R, Sousa RA, Fagundes V, Tufik, S. 2012. Sleep quality evaluation, chronotype, sleepiness and anxiety of Paralympic Brazilian athletes: Beijing 2008 Paralympic Games. British J Sports Med. 46:150-154. doi:http://dx.doi.org/10.1136/bjsm.2010.077016.

Spitzer R, Terman M, Williams J, Terman JS, Malt UF, Singer F, lewy AJ. 1999. Jet lag: clinical features, validation of a new syndrome-specifi c scale, and lack of response to melatonin in a randomized, double-blind trial. Amer J Psychiat. 156:1392-1396.

Uchida S, Shioda K, Moritay, Kubota C, Ganeko M, Takeda N. 2012. Exercise effects on sleep physiology. Front Neurol. 3:1-5.

Vercruyssen F, Blin N, l'Huillier D, Brisswalter J. 2009. Assessment of physiological demand in kitesurfing. Eur J Appl Physiol. 105:103-109.

Waterhouse J, Reilly T, Atkinson G, Edwards B. 2007. Jet lag: trends and coping strategies. The lancet. 369:1117-1129.

Williams C. 2011. Environmental factors affecting elite young athletes. Med Sport Sci. 56:150-170.

World Kite Tour. 2016. Available from: http://www.worldkitetour.com/news/World-Kite-Tour-2016/. 